\title{
Investigation on the Influence of Duobinary and CSRZ Modulation Formats on Self Phase Modulation Effect in Optical Communication Network
}

\author{
S. Selvendran ${ }^{1 *}$, A. Sivanantharaja ${ }^{2}$, K. Esakkimuthu ${ }^{3}$ \\ ${ }^{1}$ Dept. of ECE, CVR college of Engineering, Ibrahimpatnam (M), Rangareddy (D), Telangana 501 510, India. \\ ${ }^{2}$ Dept. of ECE, Alagappa Chettiar Government college of Engineering and Technology, Karaikudi - 630 003, Tamilnadu,India \\ ${ }^{3}$ Dept. of ECE, University VOC college of Engineering, Tuticorin, Tamilnadu, India \\ "Corresponding Author: selvendrans86@ gmail.com,
}

Available online at: www.isroset.org

Accepted: 11/Aug/2018, Online 31/Aug/2018

\begin{abstract}
Optical communication is a prominent technology for future communication sector because of its low power consumption, high capacity and lower attenuation. It is also affected by the detrimental effects of optical fiber such as dispersion and nonlinear effects. In this paper, the impact of Carrier Suppressed Return to Zero (CSRZ) and Duobinary modulation formats on unfavorable nonlinear Self phase modulation effect of fibers has been analyzed. Modulation formats can have also significant influence on nonlinear effect due to its spectral characteristics. The performance characteristics of this system such as BER and Q-factor are measured with the help of optisystem software. Duobinary gives Q-factor of about 5.57276 and BER of 9.68E-09 even in the case of $40 \mathrm{Gbps}$ bit rate and power 20dBm, whereas CSRZ has the Q-factor of 4.12739 and BER of $1.46 \mathrm{E}-05$ respectively.
\end{abstract}

Keywords - Fiber Nonlinearity, Self-Phase Modulation, Modulation format, Quality (Q) Factor, Bit error rate.

\section{INTRODUCTION}

With the increasing growth and demand for capacity in national, regional, and even metropolitan optical networks, high bit rate fiber transmission has recently become an essential part of the optical communication. Optical modulation format is used to impress data on an optical carrier wave for transmission over optical fiber. The simplest optical modulation format is on-off-keying (OOK) intensity modulation, which can take either of two forms: non-returnto-zero (NRZ) or return-to-zero (RZ) [1, 2]. The return-tozero (RZ) pulse is efficient for long-distance, high-bit-rate, Wavelength Division Multiplexed (WDM) transmission dispersion-managed systems [3]. The nonlinear effects such as self-phase modulation (SPM), cross-phase modulation (CPM) and four-wave mixing (FWM) occur either due to intensity dependence of refractive index of the medium or due to inelastic-scattering phenomenon [4]. Fiber Non-linear effects are just a consequence of increasing the need for high data rates, number of wavelengths, transmission lengths and optical power levels. The fiber non-linearity came into picture in 1970's but initially these effects were ignored, later studied with the development of LASERs. Increased input power affects the system as it makes SPM grow which eventually degrades the signal. SPM occurs in single channel configurations, where it basically converts optical power fluctuations into phase fluctuations in the same wave [5]. The spectral broadening of the pump pulse through self-phase modulation in a time-domain distributed Brillouin sensor has a considerable detrimental effect in the measurement, especially in the case of long distances and high-resolution pulses. Using $30 \mathrm{~ns}$ pump pulses with peak power of 276 $\mathrm{mW}$, self-phase modulation leads to a doubling of the effective gain line width after some $20 \mathrm{~km}$, which is equivalent to a contrast loss of $2 \mathrm{~dB}$ in the measurement [6]. Akira Suda analytically investigated the spectral broadening by self-phase modulation with strongly chirped optical pulses. The dispersion due to the nonlinear optical process is expressed as functions of a linear and a nonlinear initial chirp. As a result, it is found that the third-order dispersion strongly depends on the initial linear chirp and the nonlinearity for self-phase modulation [7]. T.Wuth reported that, influence of self-phase modulation on duo binary and single sideband modulation, and additionally compared the receiver sensitivity for a bit error ratio of $10 \mathrm{E}-9$ by varying fiber length and input power [8]. In this paper, we demonstrate the influence of CSRZ and duobinary modulation formats on SPM effects in optical communication. We analyzed the effects of SPM in terms of Q-factor and Bit Error Rate (BER). This paper is organized as follows, 2nd section is the experimental setup, 3rd section is the results and discussion and the final section is the conclusion. 


\section{EXPERIMENTAL SETUP}

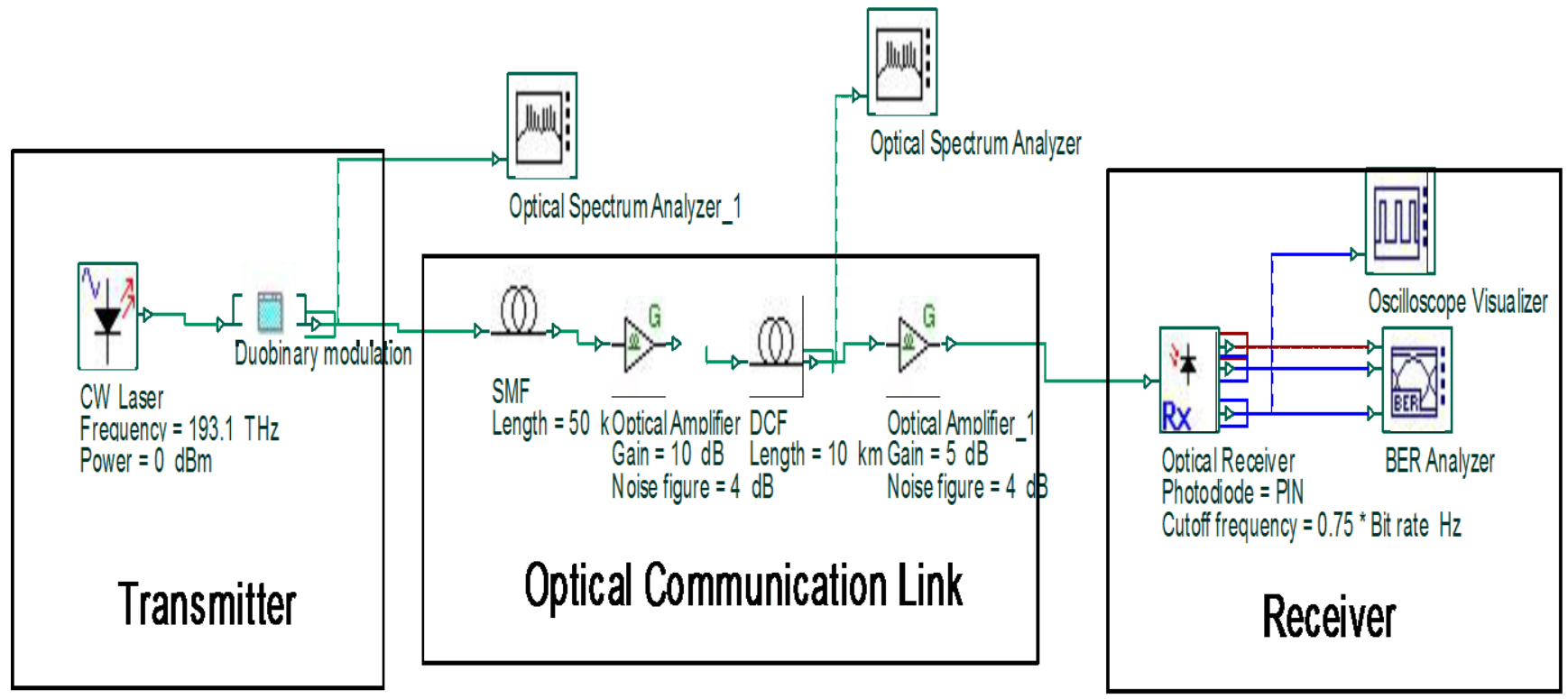

Fig.1 Optical communication setup with Duo-binary modulation

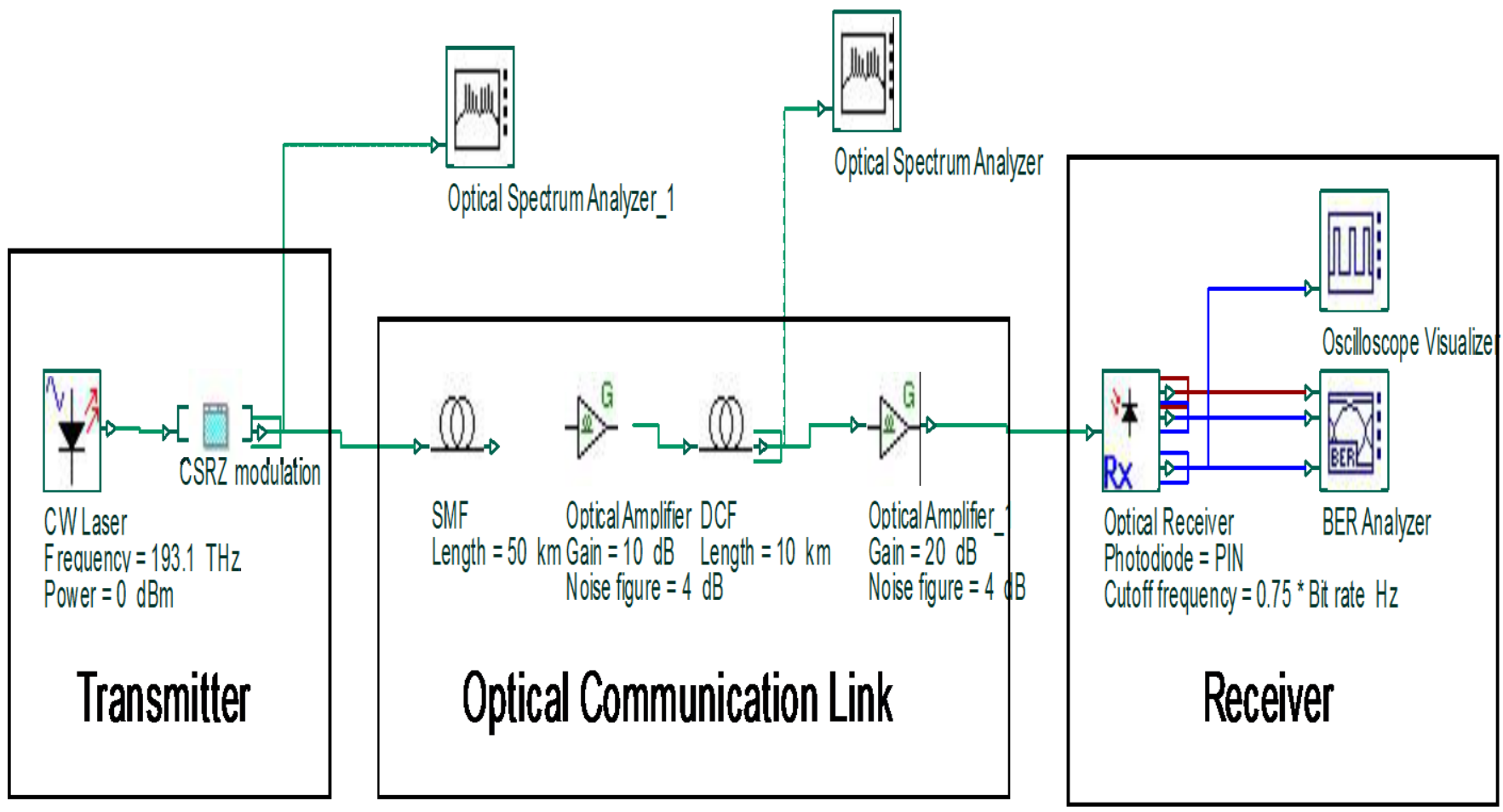

Fig.2 Optical communication setup with Duo-binary modulation.

Fig. 1 and 2 show the optical communication system setup along with 2 different modulation formats. As in fig (3), the Duobinary signal was generated by first creating an NRZ duobinary signal of pseudo random bit sequence using a precoder and a duobinary pulse generator. The generator drives the first Mach-Zhender Modulator (MZM), and then concatenates this modulator with a second modulator that is driven by a sinusoidal electrical signal with the frequency equal to the bit rate. The duobinary precoder is composed of an exclusive-or gate with a delayed feedback path. In order to obtain the recursive decoding in the receiver, the precoder is used. 


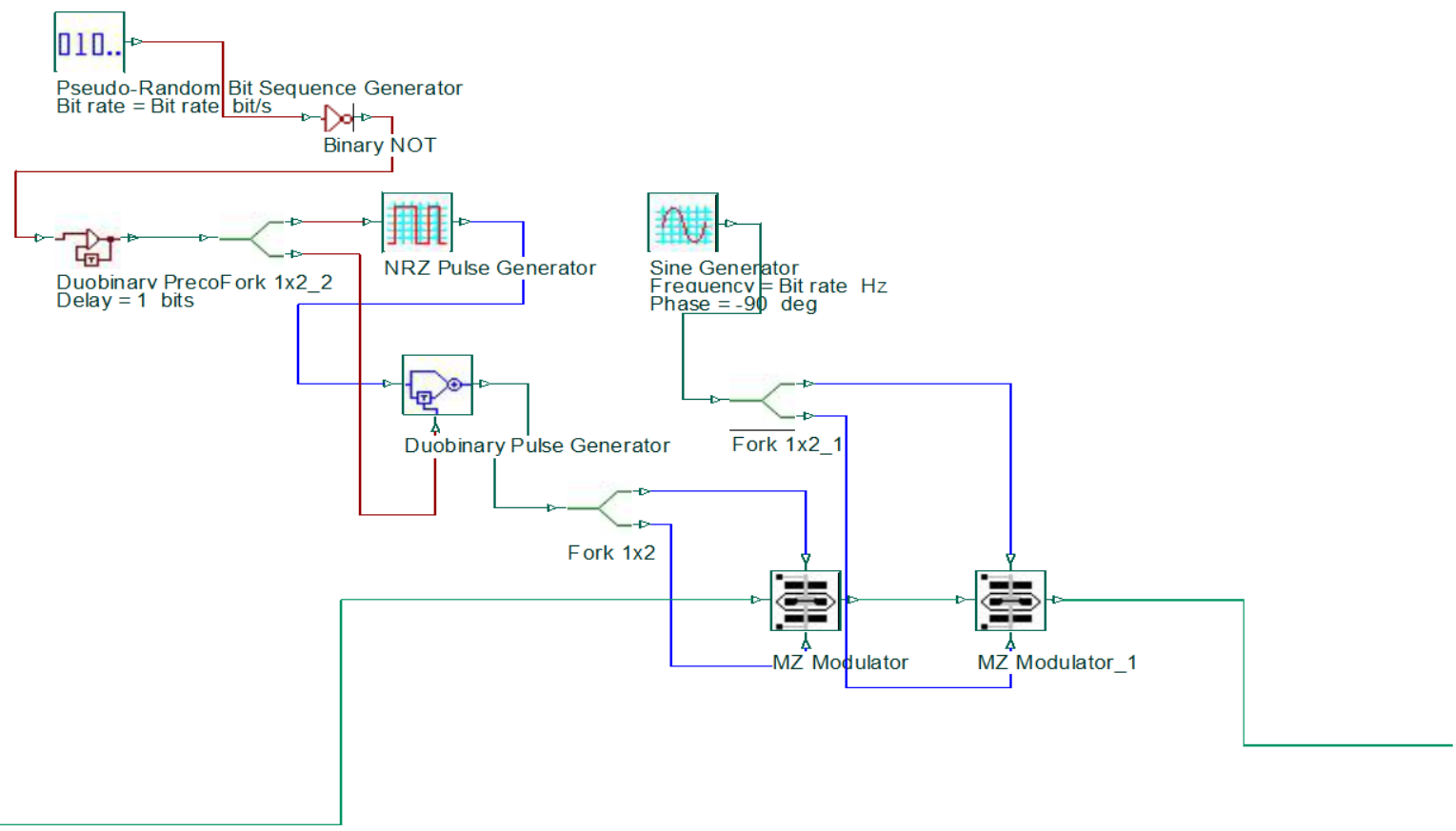

Fig.3 Duobinary subsystem
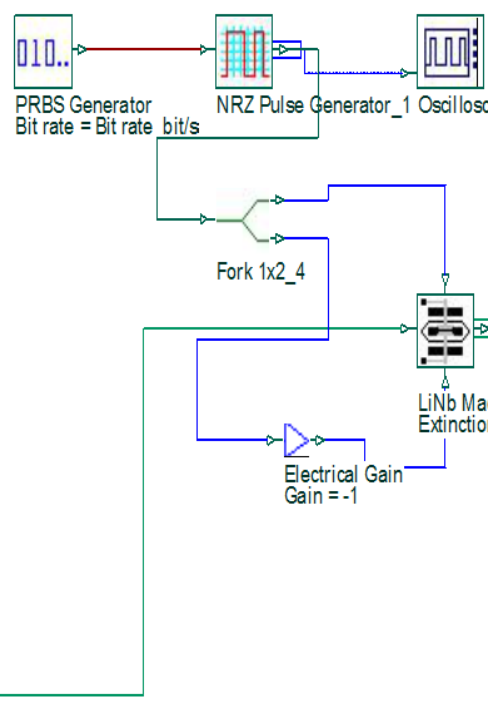

NRZ Pulse Generator_1 Oscilloscope Visualizer_2

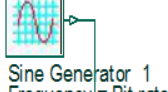

Frequency = Bit rate $/ 2 \mathrm{~Hz}$
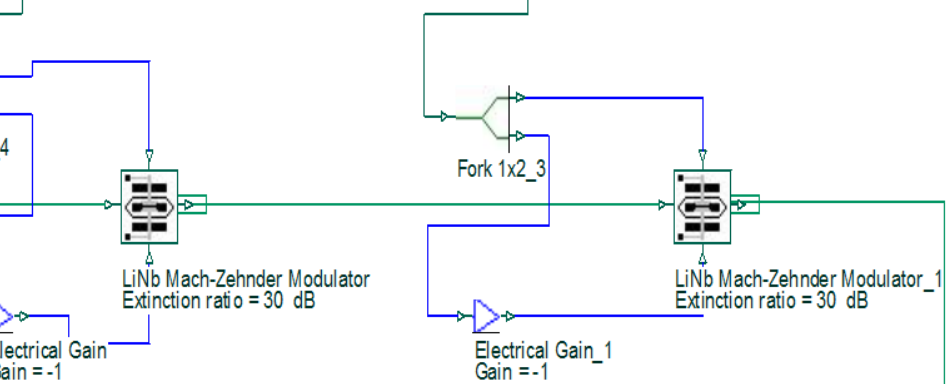

Fig. 4 CSRZ subsystem

As in fig (4), the CSRZ signal is generated in a similar way to the RZ format. However, the frequency of the sinusoidal electrical signal applied in the second MZM has half of the bit rate. The second MZM is biased in a way to provide alternating optical phases between 0 and $\pi$ for the neighboring time slots. The phase of bits ' 1 's is alternating with a difference of 180 degrees. This phase difference causes the elimination of the carrier at $193.1 \mathrm{THz}$. The modulated duobinary and CSRZ signal are transmitted through a transmission link. This transmission link is established by two fibers such as single mode fiber (SMF) of $50 \mathrm{~km}$ and dispersion compensation fiber (DCF) of $10 \mathrm{~km}$. EDFA is used in this system to eliminate transmission losses. Various fiber parameters are tabulated in Table 1. The optical receiver consists of PIN photodiode and Bessel filter. Photodiode in the transmission link is used to convert the optical to electrical signal and Bessel filter is used to eliminate the unwanted noise in the received signal. The received signal BER and Q-factor are measured using optical 
receiver and BER analyzer. The optisystem simulation parameters are given in Table 2.

Table. 1 optical Fibers parameters

\begin{tabular}{|l|l|l|}
\hline \multirow{2}{*}{ Parameters } & \multicolumn{2}{|c|}{ Fiber properties } \\
\cline { 2 - 3 } & \multicolumn{1}{|c|}{ SMF } & \multicolumn{1}{c|}{ DCF } \\
\hline Reference wavelength & $1550 \mathrm{~nm}$ & $1550 \mathrm{~nm}$ \\
\hline Fiber Length & $50 \mathrm{~km}$ & $10 \mathrm{~km}$ \\
\hline Dispersion & $17 \mathrm{ps} / \mathrm{nm} / \mathrm{km}$ & $-85 \mathrm{ps} / \mathrm{nm}^{2} / \mathrm{km}$ \\
\hline Dispersion slope & $0.075 \mathrm{ps} / \mathrm{nm}^{2} / \mathrm{km}$ & $-0.1 \mathrm{ps} / \mathrm{nm}^{2} / \mathrm{km}$ \\
\hline Effective Area & $80 \mathrm{um}^{2}$ & $55 \mathrm{um}^{2}$ \\
\hline N2 & $26 \mathrm{E}-021 \mathrm{~m}^{2} / \mathrm{w}$ & $26 \mathrm{E}-021 \mathrm{~m}^{2} / \mathrm{w}$ \\
\hline
\end{tabular}

Table 2. Optisystem simulation parameters

\begin{tabular}{|l|c|}
\hline Simulation parameters & Values \\
\hline Bit rate & 10 to $40 \mathrm{Gbps}$ \\
\hline Sequence Length & 128 \\
\hline Samples per bit & 32 \\
\hline Number of samples & 4096 \\
\hline
\end{tabular}

\section{RESULTS AND DISCUSSIONS}

Nonlinear effects are often categorized into two sets of effects. First one is those resulting from the propagation of a single channel and the second is those resulting from the interactions between WDM channels. Single channel nonlinear effects are caused mainly through self-phase modulation, where each channel alters its own phase. It leads to spectral broadening of optical pulses. It is difficult to detect separately each signal's nonlinear effects in complex WDM system. Therefore, for creating SPM effects, we use only one signal for performance estimation. We have analyzed the effects of SPM in terms of Q-factor and Bit Error Rate (BER), for which modulated continuous wave laser at wavelength of $193.1 \mathrm{THz}$ is used as a source at different power levels in the range of 0 to $25 \mathrm{dBm}$. We have also analyzed the system for two cases. The first case is the effects of SPM in Duobinary modulation. The measured parameters for the first case are tabulated in Table 3 and 4.

Table 3 Measured Q factor for the different input power and bit rate in Duobinary modulation

\begin{tabular}{|l|l|l|l|l|}
\hline \multirow{2}{*}{ Power(dBm) } & \multicolumn{4}{|c|}{ Q-factor for different Bit rates } \\
\cline { 2 - 5 } & $10 \mathrm{Gbps}$ & $20 \mathrm{Gbps}$ & $30 \mathrm{Gbps}$ & $40 \mathrm{Gbps}$ \\
\hline 0 & 93.2277 & 69.6225 & 56.4158 & 49.0455 \\
\hline 5 & 150.37 & 110.009 & 82.9196 & 76.5846 \\
\hline 10 & 217.576 & 90.4859 & 60.9226 & 48.9658 \\
\hline 15 & 125.569 & 29.6706 & 22.782 & 18.3916 \\
\hline 20 & 16.6307 & 5.53607 & 5.71804 & 5.57276 \\
\hline 25 & 8.83921 & 2.84929 & 3.20546 & 0 \\
\hline
\end{tabular}

Table.4 Measured BER for the different input power and bit rate in Duobinary modulation

\begin{tabular}{|l|l|l|l|l|}
\hline \multirow{2}{*}{ Power $(\mathrm{dBm})$} & \multicolumn{4}{|c|}{ BER for different Bit rates } \\
\cline { 2 - 5 } 0 & $10 \mathrm{Gbps}$ & $20 \mathrm{Gbps}$ & $30 \mathrm{Gbps}$ & $40 \mathrm{Gbps}$ \\
\hline 5 & 0 & 0 & 0 & 0 \\
\hline 10 & 0 & 0 & 0 & 0 \\
\hline 15 & 0 & 0 & 0 & 0 \\
\hline 20 & 0 & $6.03 \mathrm{E}-194$ & $2.16 \mathrm{E}-115$ & $4.79 \mathrm{E}-76$ \\
\hline 25 & $2.06 \mathrm{E}-62$ & $1.12 \mathrm{E}-08$ & $3.80 \mathrm{E}-09$ & $9.68 \mathrm{E}-09$ \\
\hline
\end{tabular}

The proposed system has exhibited a good performance for the bit rate of 10 Gbps. As in Table 3 and 4, Q-factor increases initially with increased power and reaches a maximum limit of 217.576 at the input power of $10 \mathrm{dBm}$ and bit rate of 10 Gbps. Then the Q-factor reduces with increasing input power level from $15 \mathrm{dBm}$. Initially at 40 Gbps bit rate and $0 \mathrm{dBm}$ power the measured Q-factor is 49.0455. But, the signal is vanished at the power of $25 \mathrm{dBm}$ in the same bit rate. So, the overall system is affected more by SPM effects at higher bit rates. The proposed system produces a good Q-factor of 5.57276 and BER of 9.68E-9 even in the case of high bit rate of $40 \mathrm{Gbps}$ and input power of $20 \mathrm{dBm}$. Fig 5. shows, Q-factor for the duobinary modulation. It decreases with increasing input power. The Q-factor drastically reduces at high input power.

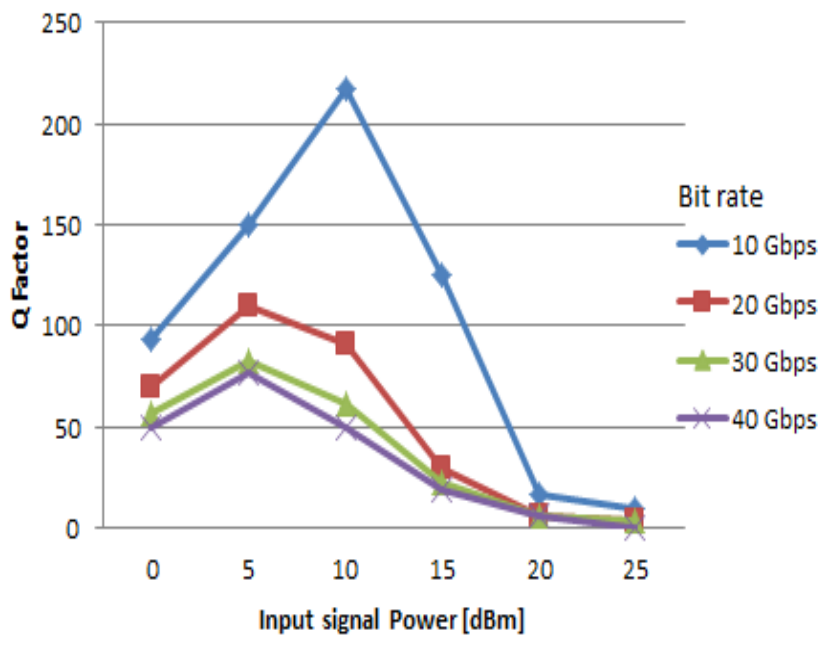

Fig.5 Q factor obtained for SPM effect in duobinary modulation

The second case is that the effects of SPM in CSRZ modulation. The measured values in second case are tabulated in Table 5 and 6. 
Table.5 Measured $\mathrm{Q}$ factor for the different input power and bit rate in CSRZ modulation

\begin{tabular}{|l|l|l|l|l|}
\hline \multirow{2}{*}{ Power(dBm) } & \multicolumn{4}{|c|}{ Q-factor for different Bit rates } \\
\cline { 2 - 5 } & $10 \mathrm{Gbps}$ & $20 \mathrm{Gbps}$ & $30 \mathrm{Gbps}$ & $40 \mathrm{Gbps}$ \\
\hline 0 & 99.1019 & 73.1474 & 60.6608 & 50.8688 \\
\hline 5 & 161.801 & 106.43 & 83.0796 & 71.0975 \\
\hline 10 & 123.821 & 81.5784 & 42.3614 & 42.941 \\
\hline 15 & 26.4195 & 26.9348 & 14.5306 & 15.0503 \\
\hline 20 & 10.9605 & 4.8559 & 3.67006 & 4.12739 \\
\hline 25 & 5.28852 & 2.97461 & 0 & 0 \\
\hline
\end{tabular}

Table.6 Measured BER for the different input power and bit rate in CSRZ modulation

\begin{tabular}{|l|l|l|l|l|}
\hline \multirow{2}{*}{ Power(dBm) } & \multicolumn{4}{|c|}{ BER for different Bit rates } \\
\cline { 2 - 5 } & $10 \mathrm{Gbps}$ & $20 \mathrm{Gbps}$ & $30 \mathrm{Gbps}$ & $40 \mathrm{Gbps}$ \\
\hline 0 & 0 & 0 & 0 & 0 \\
\hline 5 & 0 & 0 & 0 & 0 \\
\hline 10 & 0 & 0 & 0 & 0 \\
\hline 15 & $2.55 \mathrm{E}-154$ & $2.84 \mathrm{E}-160$ & $2.45 \mathrm{E}-48$ & $1.03 \mathrm{E}-51$ \\
\hline 20 & $2.89 \mathrm{E}-28$ & $5.10 \mathrm{E}-77$ & $1.02 \mathrm{E}-04$ & $1.46 \mathrm{E}-05$ \\
\hline 25 & $3.86 \mathrm{E}-08$ & 0.001438 & 1 & 1 \\
\hline
\end{tabular}

As in Table 5 and 6, Q-factor increases initially with increased power, reaches the peak value of 161.801 , at the input power of $5 \mathrm{dBm}$ and bit rate of $10 \mathrm{Gbps}$. Then the Qfactor reduces with increasing input power level from 10 $\mathrm{dBm}$. At $40 \mathrm{Gbps}$ bit rate and power $0 \mathrm{dBm}$, the measured Qfactor is 50.8688. But, the signal is not present at the power of $25 \mathrm{dBm}$ in the same bit rate. So, the overall system is affected more by SPM effects at higher bit rates. The designed CSRZ system produces good Q-factor of 4.12739 and BER of 1.46E-5 even in case of high bit rate of $40 \mathrm{Gbps}$ and input power of $20 \mathrm{dBm}$. Fig 6. shows, the Q-factor with increasing input power for the CSRZ modulation format.

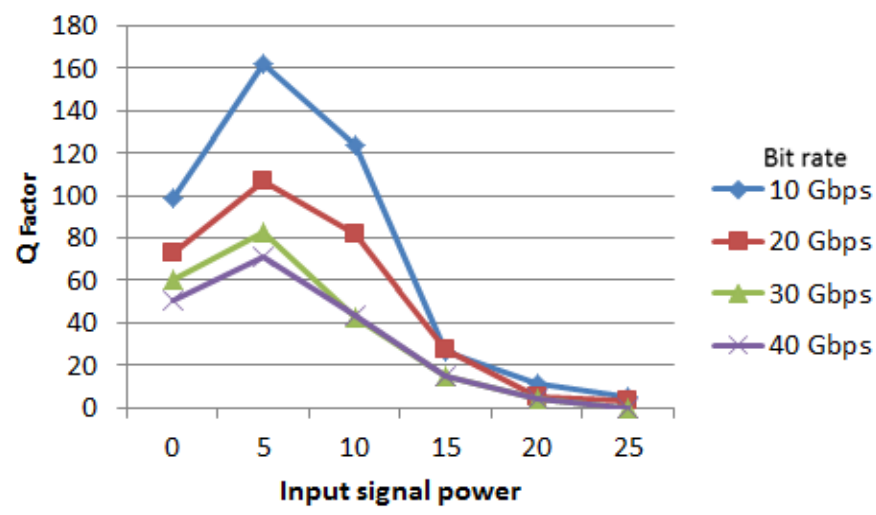

Fig. 6 Measured Q factor with SPM effect in CSRZ modulation

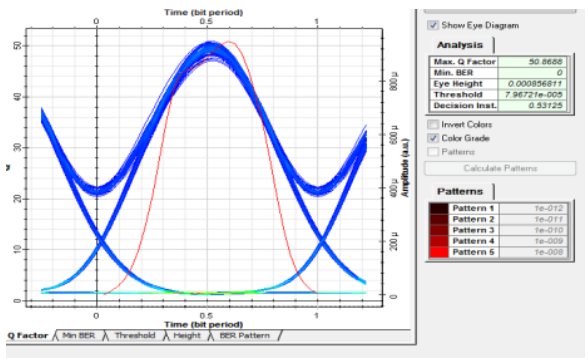

Fig.7 Eye diagram of Duobinary system for $40 \mathrm{Gbps}$ data rate and input power of $0 \mathrm{dBm}$

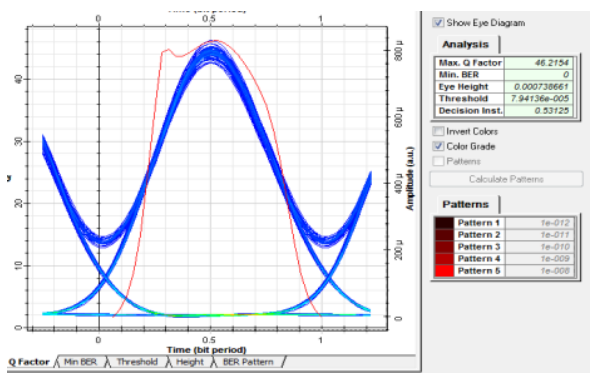

Fig.8 Eye diagram of CSRZ system for $40 \mathrm{Gbps}$ data rate and input power of $0 \mathrm{dBm}$

Fig. 7 and 8 show the eye diagrams at input power level of 0 $\mathrm{dBm}$ and bit rate of 40 Gbps for duobinary and CSRZ systems respectively

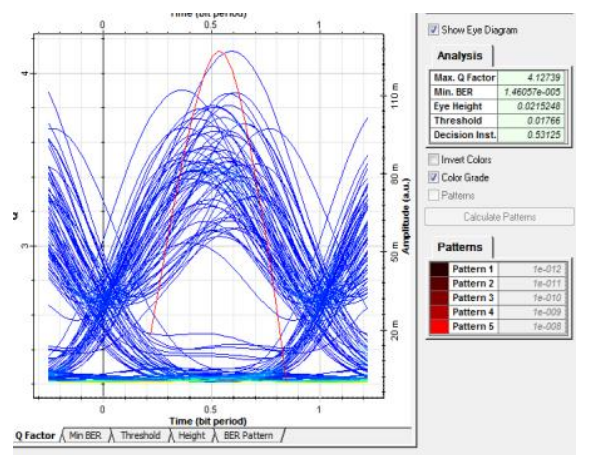

Fig.9 Eye diagram of Duobinary system for $40 \mathrm{Gbps}$ data rate and input power of $20 \mathrm{dBm}$

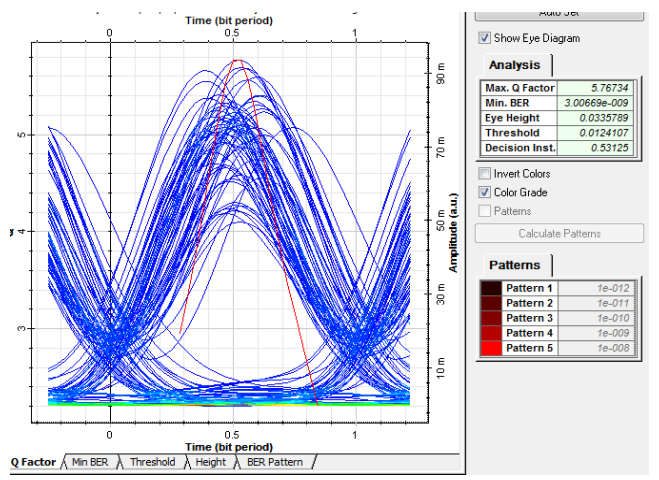

Fig.10 Eye diagram of CSRZ system for $40 \mathrm{Gbps}$ data rate and input power of $20 \mathrm{dBm}$ 
Fig. 9 and 10 show the eye diagrams at input power level of $20 \mathrm{dBm}$ and bit rate of $40 \mathrm{Gbps}$ for duobinary and CSRZ systems respectively.

From the results of Duobinary and CSRZ system, Duobinary gives better Q-factor of 5.57276 and BER of 9.68E-09 performance for the case of $40 \mathrm{Gbps}$ bit rate and 20 $\mathrm{dBm}$ input power whereas CSRZ has the Q-factor of 4.12739 and BER of $1.46 \mathrm{E}-05$ respectively for the same input conditions.

\section{CONCLUSION}

In this paper, self-phase modulation effects on the duobinary and CSRZ modulation formats have been analyzed using the optisystem software. The proposed Duobinary system produces good Q-factor of 5.57276 and BER of $9.68 \mathrm{E}-9$ for the case of high bit rate of $40 \mathrm{Gbps}$ and input power of 20 $\mathrm{dBm}$. But, CSRZ system produces Q-factor of 4.12739 and BER of $1.46 \mathrm{E}-5$ only under similar input conditions. Hence it is concluded that the duobinary system has better performance for SPM effects than the CSRZ system.

\section{REFERENCE}

[1]. V. Bobrovs, J. Porins, G. Ivanovs. Influence of Nonlinear Optical Effects on the NRZ and RZ Modulation Signals in WDM Systems // Electronics and Electrical Engineering. - Kaunas: Technologija, 2007. - No. 4(76). - P. 55-58.

[2]. Virendra kumar, A.K.Jaiswal, Mukesh kumar, Nilesh agrawal, Rohini Saxena, "Design and Performance Analysis of Optical Transmission system" IOSR Journal of Engineering (IOSRJEN), ISSN (e): 2250-3021, ISSN (p): 2278-8719Vol. 04, Issue 05 (May. 2014), ||V3|| PP 22-26

[3]. Varun Marwaha, Ankur Singhal, Satinder Pal Ahuja, "Performance Evaluation of Modulation Format for Optical System" International organization of Scientific Research (IJECT), Vol. 3, Issue 1, Jan. - March 2012.

[4]. S. P. Singh and N. Singh "Nonlinear Effects In Optical Fibers: Origin, Management And Applications" Progress In Electromagnetics Research, PIER 73, 249-275, 2007.

[5]. Narender Kumar Sihval and Amit Kumar Garg "Simulation and Analysis of Self Phase Modulation Fiber Non Linearity" Journal of Multidisciplinary Engineering Science and Technology (JMEST), ISSN: 3159-0040, Vol. 2 Issue 6, June - 2015.

[6]. Stella M. Foaleng. et al., "Detrimental effect of self-phase modulation on the performance of Brillouin Distributed fiber sensors" Optical letters, vol. 36, Issue 2, PP. 97-9.

[7]. 7. Akira Suda and Takanori Takeda "Effects of Nonlinear Chirp on the Self-Phase Modulation of Ultra short Optical Pulse" Appl. Sci., Vol. 2, Issue 2, PP.549-557; doi:10.3390/app2020549.

[8]. T.Wuth, W.Kaiser and W.rosenkranz "Impact of Self-Phase Modulation on Bandwidth Efficient Modulation Formats" Optical Fiber Communication Conference and Exhibit, 2001. OFC 2001, DOI: 10.1109/OFC.2001.927923.

\section{AUTHORS PROFILE}

Dr. S. Selvendran has finished his B.E. in Electronics and Communication Engineering, M.E. in Optical Communication Engineering and Ph.D. in Nonlinear Fiber Optics. Currently he is working as an Associate Professor in CVR college of Engineering, R.R district, Telangana (An Autonomous Engineering College). He has published 31 papers in the reputed international journals and 11 papers in international and national conferences.

Dr A. Sivanantha Raja has finished his B.E. in Electronics and Communication Engineering, M.E. in Microwave and Optical Communication Engineering and Ph.D. in Biomedical Applications. Currently he is working as an Associate Professor in A.C. Govt. College of Engineering and Technology, Karaikudi (An Autonomous

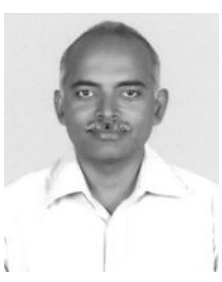
Engineering College). 9 Ph.D. scholars, 2 M.S. By Research scholars and more than 75 M.E. thesis in the field of optical communication networks, photonic crystalbased component devices and biomedical applications have been guided by him. He has published around 75 papers in the reputed international journals and more than 35 papers in the international and national conferences and he has contributed a book chapter.

Dr. K.Esakki Muthu is an Assistant Professor at the University VOC. College of Engineering. He received his B.E. degree from Madurai Kamaraj University in 2001 and M.E. degree in Optical Communication from the Anna University in 2005. He has completed his Ph.D. degree in the field of MM-Wave Radio over Fibre systems in Anna University, Chennai. He has published more than 20 research articles in the reputed Journals and Conferences. His current research interests include MM-Wave Radio over Fiber, Photonic Crystal Devices, and Wireless Communication. 